\title{
Exploration of clinical teaching reform under the trend of modern medical development
}

\author{
Zhanao Liu', a \\ ${ }^{1} \mathrm{XI}, \mathrm{AN}$ MEDICAL COLLEGE, Shaanxi ,XI,AN , 710309 \\ aliuzhanao19833@126.com
}

Keywords: Modern medicine; clinical medicine; teaching reform

\begin{abstract}
With the continuous development of social economy and the improvement of people's living standard, trained in the traditional medical teaching mode of medical students at the beginning of the new pattern of the "bio - environment - social - psychological - Social Medical Engineering" demand showed some disadvantages, limiting their own development. In order to realize the strategic goal of "Healthy China 2020", it is imperative to reform the current teaching mode of clinical medicine. In this paper, the content will be discussed and analyzed in order to provide reference for the related research.
\end{abstract}

\section{Introduction}

Since the college entrance examination was resumed in 1977, education has made remarkable progress. In the aspect of higher medical education, the direction of running a school is more clear. It is precisely because of this. The level of higher medical education in China has reached an unprecedented level. Not only that, in order to achieve the purpose of lifelong learning, but also the establishment of a remedial education, medical education after graduation, continuing medical education of the continuum of higher education system [1]. However, it is worth noting that, with the development of social economy and the improvement of people's living standard, trained in the traditional medical teaching mode of medical students at the beginning of the new pattern of the "bio - environment - social - psychological - Social Medical Engineering" demand showed some disadvantages, limiting their own development. At the same time, the rapid growth of medical services between the contradictions and problems, the current population aging society as well as human population, disease spectrum changes and death spectrum and so on, to the current teaching mode of clinical medicine requires rigorous test and new teaching. Therefore, in healthy China 2020 strategic planning, the state proposed establishing a large health, health, big medical concept and the implementation of the model change, focus forward, the transformation of integration strategy [2]. In order to reach this goal, in the development trend of modern medicine, clinical medicine teaching reform, this article will be discussed and analyzed in this paper, in order to provide reference for related research.

\section{Development trend of clinical medicine teaching under the new strategic goal}

Clinical medicine is a very practical subject. The basic purpose of this discipline is to train students' practical ability. Therefore, the goal of the development of clinical teaching under the new strategic goal is not just to help patients relieve pain, but also to ensure that patients in the psychological, physiological and social needs. In this regard, the medical purpose (GOM) international project research center to the full range of traditional medicine to examine, proposes the purpose of clinical medicine of the development of modern medicine, mainly as follows: [3] disease prevention and injury to the body, promoting and safeguarding human health; the treatment and cure of disease in order to slow down by the disease; patients with pain and pain; to prevent premature death, promote euthanasia.

Therefore, this requires the new period of clinical medical students should not only have a solid 
theoretical foundation and clinical skills, but also should constantly improve their own knowledge structure, grasp the careful analysis ability, excellent training in the daily work of the professional ability, quick observation and accurate judgment. Under the request of the new strategic goal, the clinical medical students will be a complex of knowledge, quality and ability. The goal of the reform of clinical medical education is to cultivate the compound talents with the progress of all aspects.

\section{Strategies of clinical medicine teaching reform under the trend of modern medical development}

\subsection{Changes in the traditional concept of clinical medicine teaching}

The traditional teaching environment in the formation of China's thousands of years, there is a great disadvantage, that most of the students are often in a passive state of learning, which often leads to decreased learning efficiency and learning effect is poor, it is difficult for students to stimulate interest in learning of professional knowledge, lack of enthusiasm for learning. Clinical medicine is a very practical subject, solid professional basis is necessary quality after work, major in clinical medicine in the process of teaching reform in basic education must pay attention to the combination of theory and practice of students, to strengthen students' clinical operation basic skill training. Only in this way, can we cultivate students majored in clinical thinking and disinterested scientific research ability, improve students' clinical ability, rapid growth as a professional can take charge as chief of personnel.

Therefore, the teaching reform of clinical medicine the need to change the traditional clinical teaching concept, should not only pay attention to the basic theory of knowledge and learning, it should be combined with the social development, the progress of science and technology and medical and health development needs, will gradually change to the teaching focus not only teach the basic theoretical knowledge of students, but also to strengthen the cultivation of clinical innovation the students' ability of education ideas. The reform of clinical teaching should aim to teach the students how to learn and abandon the past blindly instill teaching theoretical knowledge, to stimulate students' teaching ways of acquiring knowledge, and knowledge in the use and exercise constantly, to discover and solve problems. Only in this way can we help students to update the existing knowledge and keep up with the latest information on the subject.

\subsection{Improve the quality of clinical teachers}

The clinical medical students in the new period should have the ability of independent thinking and creativity, which has to be cultivated and trained gradually in the daily teaching process. However, in the five year of clinical medicine in the learning process, three years ago is mainly the theory of knowledge learning in schools, teaching contents more emphasis on theory and lack of practice; after two years is mainly for training and internship in the hospital, this period mainly by clinical medical students in teaching hospital. Due to the current hospital is mainly based on clinical medicine, clinicians themselves have extremely demanding task, it is difficult to do professional teaching. Not only that, some hospitals will also learn a doctor or junior resident students assigned to the clinical teaching work, which leads to the clinical teaching force are insufficient, it is difficult to really achieve the purpose of teaching clinical [4]. In addition, due to the hospital internship and internship, for the exam requirements are relatively loose, no quantitative assessment criteria of teaching achievement, also easy to cause the teachers lack of liability insurance, the enthusiasm of students with poor results.

In this regard, the Department should be responsible for teaching hospital in our hospital clinical teaching work for the overall planning, clear teaching tasks and objectives of the existing teachers, and summarized the distribution, selection of medical ethics, excellent professional and technical teachers students as clinicians, and develop the strict and reasonable teaching evaluation system and evaluation index. And the related incentive mechanism, to improve the clinical teaching work, to achieve the purpose of teaching reform. In addition, the hospital also can use a variety of teaching methods, such as [5] invited experts to give lectures, seminars, training and increasing the use of opportunities for youth learning and teaching ability, or the delivery of training to improve their own 
quality. Teachers should also acquire and master new clinical knowledge through various forms, reform and innovate the clinical teaching methods, and make good use of modern media and other teaching equipment, so as to increase the interest of clinical teaching.

\subsection{Set up the teaching course}

Clinical medical talents in the new century should have the German high school Bo and medicine fine features. This is the future work of the lifelong pursuit. It is the first stage to achieve the goal of setting up a reasonable teaching course to help students lay a solid foundation. Due to the wide range of courses in medical colleges and universities, including medical courses, humanities courses, compulsory courses, elective courses, and so on, how to set up a passable. Through the existing data shows, at present in the country to do the Zhongshan University and the Shantou University [6] is relatively good, the two medical colleges through the model, setting American and Chinese University Hong Kong courses to abandon the traditional "break the normal procedure, subject centered" old teaching mode, bold use of cross set new integrated curriculum. Effective teaching effect is achieved. For example, through the optimization and integration of basic medical courses and clinical courses, reform the traditional teaching setting module, change structure, basis of human learning, cardiovascular respiratory, digestive and nutrition, blood - infection immunity, neurological, musculoskeletal, reproductive sex development and growth, the balance of the body, and the mechanisms of disease drug treatment of the ten basic modules are assigned to different semester learning, let students continue to receive, have a sense of the level of medical knowledge system, help students grasp every medical knowledge system and associated with the more solid.

\subsection{Improve the teaching quality of clinical practice}

3.4.1 Strengthen the cultivation of students' basic skills

With more and more people begin to pay attention to their own quality of life, "the traditional clinical medicine target lives" to further deepen the. In this process, it is necessary to improve the basic clinical skills of medical college students, and it is also an important part of cultivating the practical ability. First of all, we should attach importance to the cultivation of students' writing ability. Medical instruments are an important part of the actual work process, but also an objective indicator to evaluate the ability of clinicians to work [7]. In this regard, the homeopathic college teachers should be careful to explain the writing process, methods, and other matters needing attention, and strictly control, improve the quality and efficiency of medical instruments. Secondly, in the practice of the students, teachers should also be combined with the actual clinical cases, the content of the demonstration to the students on how to conduct a physical examination, medical history collection, consolidate and improve the students to master the basic theory. For example, in the clinical teaching process, teachers can according to the actual work in accordance with the clinical cases and problems, to the students to ask questions and enlightening, to mobilize the initiative of students' professional knowledge learning, and stimulate students' learning of professional knowledge to. Through the student's thinking and research, combined with the teacher's tips for logical reasoning, summary and analysis, in the study of clinical knowledge, but also mastered the different learning methods, two birds with one stone.

\subsubsection{Focus on training students' clinical research ability}

The subject of clinical medicine has been paid more and more attention since it came into being, which is closely linked to the characteristics of comprehensiveness, service, sociality, science and technology. With the rapid development of social economy and science and technology, clinical medical technology is required to produce a leap. Therefore, both the disinterested professional students or the future as a clinician, need to keep pace with the times, and constantly explore the spirit of innovation. This requires higher medical colleges and universities in the teaching reform, will attach importance to the students' scientific research ability as a key direction of training. Therefore, the process of clinical teaching in medical colleges and universities, teachers should pay attention to cultivate students of literature retrieval ability of [8], review writing ability for students to participate in lectures, creating academic forums, professional opportunities, allows students to keep abreast of the latest medical research achievements, science of thinking has been inspired, so as to improve the students' future the scientific research ability, maintain the advanced nature. 


\subsection{Improve the English professional level of medical students}

English as a world language is also an important means for medical students to get the latest information and understand the theoretical knowledge. However, the current level of professional English of medical students is unsatisfactory, the existing research results show that the [9] into the clinical practice of medical students basic English level six pass rate of 55\%, medical English words pass rate is only $26 \%$. The importance and urgency in improving medical students' professional English level in the medical colleges should the students at the beginning of the school, first set for the basic English course, according to the situation in the promotion of professional English, strengthen the construction of medical English teaching materials, provide basic guarantee for medical English teaching. At the same time, in the process of English teaching, the students' ability of listening, speaking, reading and writing should be taken as the development goal.

\section{Summary}

Educating reform of clinical medicine is a necessary course. With the continuous development of economy and society, people pay more and more attention to their quality of life. "patient-centered medical service concept towards health centered transformation, the concept of health is more perfect. The development of a new era of clinical medicine from individual disease prevention and treatment of single mode gradually to the multi polarization development, but is no longer confined to individual patients, but also from many aspects of biological, social and psychological environment, group oriented and community greater development. This is to put forward higher requirements for the new period of clinical medical students. Clinical teaching reform is also the fundamental goal, needs the joint efforts of every clinical medical workers, and strives to further solve the human suffering.

\section{References}

[1] Ping H E. Exploration in the Reform of Medical Microbiology Teaching on Eight-year MD Program[J]. Microbiology, 2008, 35(8):1319-1321.

[2] Ping H E. Exploration in the Reform of Medical Microbiology Teaching on Eight-year MD Program[J]. Microbiology, 2008, 35(8):1319-1321.

[3] Jinlan. The Reform Exploration on the Computer Basic Education of Non-Computer Major under the General Education Model in China[J]. Bmc Cancer, 2013, 13(1):1-11.

[4] Martimianakis M A, Hafferty F W. Exploring the interstitial space between the ideal and the practised: humanism and the hidden curriculum of system reform[J]. Medical Education, 2016, 50(3):278-280.

[5] Guo J H, Liu W J. Exploration of Teaching Reform of Rubber and Plastic Mold Design Course for Polymer Materials Specialty[J]. Polymer Bulletin, 2014, 44(3):81-84.

[6] Jones M. Measuring the World: Exploration, Empire and the Reform of the Royal Geographical Society, c. 1874-93[J]. Annals of Hematology, 2012, 89(3):309-16.

[7] Ze-Quan J I, Deng S J, Lin M H. A study on the teaching reform based on the networked environment[J]. Medical Education, 2005.

[8] Loy B A. Genomic Testing and the Quality of Care: Exploring the Impact of Healthcare Reform[J]. Genome Research, 2013, 15(1):120-5.

[9] Knuuti J, Kajander S, Mäki M, et al. Quantification of myocardial blood flow will reform the detection of CAD[J]. Journal of Nuclear Cardiology, 2009, 16(4):497-506. 